\title{
Computer-assisted Foreign Language Teaching: Theory and Practice
}

\author{
Youwen Yang \\ Beijing Foreign Studies University, Beijing 100089, China; Wenzhou University, Zhejiang 325035, China \\ Email: youwiny@yahoo.com.cn
}

\begin{abstract}
One of the important components of applied linguistics is to study how computers are used in language teaching. This paper tries to scan the three stages of computer-assisted language learning (CALL) development, the relationship between CALL and linguistic theories and research methods. The paper also discusses some practical issues on CALL in China.
\end{abstract}

\section{Index Terms - CALL, theoretical approaches, CALL research, CALL practice}

Recent years have seen a bloom of interest in using computers for language teaching and learning. A decade ago, the use of computers in the language classroom was of concern only to a small number of specialists. However, with the availability of multimedia computing and the Internet, the role of computers in language instruction has now become an important issue confronting large numbers of language teachers throughout the world. This specific field is usually called computer-assisted language learning (CALL). The acronym CALL will be used as a short-cut term, for sake of brevity and convenience, which includes computer-assisted instruction (CAI), computer-assisted language teaching (CALT), computer-assisted language testing (CALT), as well as e-learning (Gu, 2006).

\section{THE HISTORY OF CALL}

Computers have been used for language teaching since the 1960s. The history of CALL can be roughly divided into three main stages: Structural /behavioristic CALL, communicative CALL, and integrative CALL (Warschauer, 2000). Each stage corresponds to a certain level of technology as well as a certain pedagogical approach. Table 1 below shows the three stages of CALL.

\begin{tabular}{|l|l|l|l|}
\hline Stage & $\begin{array}{l}\text { 1970s-1980s: Structural/ behavioristic } \\
\text { CALL }\end{array}$ & 1980 s-1990s: Communicative CALL & $\begin{array}{l}\text { 21st Century: Integrative } \\
\text { CALL }\end{array}$ \\
\hline Technology & Mainframe & PCs & Multimedia and Internet \\
\hline $\begin{array}{l}\text { English-Teaching } \\
\text { Paradigm }\end{array}$ & Grammar-Translation \& Audio-Lingual & Communicative Language Teaching & Content-Based, ESP/EAP \\
\hline $\begin{array}{l}\text { View of Language } \\
\text { Principal Use of } \\
\text { Computers }\end{array}$ & Structural (a formal structural system) & $\begin{array}{l}\text { Cognitive (a mentally-constructed } \\
\text { system) }\end{array}$ & $\begin{array}{l}\text { Socio-cognitive (developed } \\
\text { in social interaction) }\end{array}$ \\
\hline \begin{tabular}{l} 
Principal Objective \\
\hline
\end{tabular} & Accuracy & Communicative Exercises & Authentic Discourse \\
\hline
\end{tabular}

Structural /behavioristic CALL was conceived in the 1950s and implemented in the 1960s and 1970s. Informed by the behaviorist learning model, this mode of CALL featured repetitive language drills, referred to as drill-and-practice. The best-known tutorial system, PLATO, ran on its own special hardware consisting of a central computer and terminals and featured extensive drills, grammatical explanations, and translation tests at various intervals (Ahmad, Corbett, Rogers, \& Sussex, 1985).

Communicative CALL emerged in the late 1970s and early 1980s, at the same time that behavioristic approaches to language teaching were being rejected at both the theoretical and pedagogical level, and when new personal computers were creating greater possibilities for individual work. Communicative CALL stressed that computer-based activities should focus more on using forms than on the forms themselves, teach grammar implicitly rather than explicitly, allow and encourage students to generate original utterances rather than just manipulate prefabricated language, and use the target language predominantly or even exclusively (Jones \& Fortescue,1987; Phillips, 1987). Popular CALL software developed in this period included text reconstruction programs (which allowed students working alone or in groups to rearrange words and texts to discover patterns of language and meaning) and simulations (which stimulated discussion and discovery among students working in pairs or groups).

Integrative CALL shifts to a perspective which seeks both to integrate various skills (e.g., listening, speaking, reading, and writing) and also integrate technology more fully into the language learning process. In integrative approaches, 
students learn to use a variety of technological tools as an ongoing process of language learning and use, rather than visiting the computer lab on a once a week basis for isolated exercises.

\section{MAJOR THEORETICAL APPROACHES TO CALL}

While the changes in language teaching are often characterized in terms of a polar shift from structural to communicative, we usually perceive a more complex overlapping of three theoretical movements--structural, cognitive, and socio-cognitive--in the recent history of language teaching (Kern \& Warschauer, 2000). Because each of these three theoretical perspectives has influenced how computer technology has been used in language teaching, we will illustrate these three major theoretical approaches to CALL briefly.

\section{A. Structural-behavioral Approaches to CALL}

The earliest CALL programs, consisting of grammar and vocabulary tutorials, drill and practice programs, and language testing instruments, strictly followed the computer-as-tutor model. Developed originally for mainframe computers in the 1960s and 1970s, though still used in different variations today, these programs were designed to provide immediate positive or negative feedback to learners on the formal accuracy of their responses. This was consistent with the structuralist approach which emphasized that repeated drilling on the same material was beneficial or even essential to learning.

\section{B. Cognitive Approaches to CALL}

In line with cognitive/constructivist views of learning, the next generation of CALL programs tended to shift agency to the learner. In this model, learners construct new knowledge through exploration of what Seymour Papert has described as "microworlds", which provide opportunities for problem-solving and hypothesis-testing, allowing learners to utilize their existing knowledge to develop new understandings. Extending a tradition of thought popularized by John Dewey and Alfred Whitehead that learning occurs through creative action, Papert (1980) and his colleagues at the M.I.T. Media Laboratory flip the earlier computer-as-tutor metaphor on its head, seeing computers as things to be controlled by, rather than controlling learners. The computer provides tools and resources, but it is up to the learner to do something with these in a simulated environment (e.g., in Papert's Turtle Logo program, learners program a turtle to carry out their instructions).

\section{Socio-cognitive Approaches to CALL}

With socio-cognitive approaches to CALL we move from learners' interaction with computers to interaction with other humans via the computer. The basis for this new approach to CALL lies in both theoretical and technological developments. Theoretically, there has been the broader emphasis on meaningful interaction in authentic discourse communities. Technologically, there has been the development of computer networking, which allows the computer to be used as a vehicle for interactive human communication. Computers can play as mediation tools that shape the ways we interact with the world (e.g., accessing and organizing information through databases, spreadsheets, and word processors). Word processors, for example, facilitate the invention, revision, and editing processes of writing, allowing quick, easy (and reversible) reshaping of text. The purpose of programs based on this socio-cognitive approach was to allow the learner to reconstruct the original texts and, in the process, to develop their own constructions of language. Computer networking allows a powerful extension of the computer-as-tool, in that it now facilitates access to other people as well as to information and data.

To summarize, the computer can play multiple roles in language teaching. It originated on the mainframe as a tutor that delivers language drills or skill practice. With the advent of multimedia technology on the personal computer, it serves as a space in which to explore and creatively influence microworlds. And with the development of computer networks, it now serves as a medium of local and global communication and a source of authentic materials. This multiplicity of roles has taken CALL far beyond the early "electronic workbook" variety of software that dominated the second and foreign language marketplace for years and has opened up new ways in foreign language teaching. These trends are summarized in Table 2 below.

TABLE 2:

THe Role of CALL in STRUCtUral, COGNITIVE, AND SOCIO-COGNITIVE FramewORKS

\begin{tabular}{|c|c|c|c|}
\hline & Structural & Cognitive & Socio-cognitive \\
\hline $\begin{array}{c}\text { What is the principal } \\
\text { role of computers? }\end{array}$ & $\begin{array}{c}\text { To provide unlimited drill, } \\
\text { practice, tutorial explanation, } \\
\text { and corrective feedback. }\end{array}$ & $\begin{array}{c}\text { To provide language input and } \\
\text { analytical and inferential tasks. }\end{array}$ & $\begin{array}{c}\text { To provide alternative contexts for } \\
\text { social interaction; to facilitate access } \\
\text { to existing discourse communities and } \\
\text { the creation of new ones. }\end{array}$ \\
\hline
\end{tabular}

\section{RESEARCH ON CALL}

Just as the paradigms of CALL have changed, so has research on the role of computers in the language classroom. 
Early CALL research focused mostly on the language performance of students who had used CALL programs, attempting to determine whether those programs were superior to other methods for maximizing structural accuracy. The cognitive paradigm brought about research that looked at the development of individual processes, strategies, and competencies, using measures such as motivational surveys, observations, recordings of keystrokes, and think-aloud protocols. The socio-cognitive paradigm and an emphasis on learning through computer networks have brought about a focus on the way that discourse and discourse communities develop during use of computer networks (Kern \& Warschauer, 2000). Table 3 summarizes the implications for research methods of the various CALL approaches.

TABLE 3:

RESEARCH IMPLICATIONS FOR VARIOUS CALL APPROACHES

\begin{tabular}{|l|l|l|l|}
\hline & Structural & Cognitive & Socio-cognitive \\
\hline orientation & product & cognitive processes & social and cognitive processes \\
\hline methodology & $\begin{array}{l}\text { quantitative: experimental-control } \\
\text { comparisons }\end{array}$ & both quantitative and qualitative & $\begin{array}{l}\text { principally qualitative: discourse analysis, } \\
\text { analysis of sociocultural context }\end{array}$ \\
\hline $\begin{array}{l}\text { principal kinds } \\
\text { of data }\end{array}$ & $\begin{array}{l}\text { quantities/frequencies of words, } \\
\text { errors, structures }\end{array}$ & $\begin{array}{l}\text { think-aloud protocols, } \\
\text { questionnaires, computer-recorded } \\
\text { data (e.g., keystrokes) }\end{array}$ & $\begin{array}{l}\text { transcriptions of social interactions, } \\
\text { ethnographic observations and interviews }\end{array}$ \\
\hline
\end{tabular}

\section{ISSUES OF PRACTICE ON CALL}

Viewed against the CALL history in terms of the global context, CALL in China seems to have no history. Computers applied for educational purposes are only a very recent event. Nevertheless, the turn of the millennium witnessed cyber rush in China with some CALL faculties established within a very short space of time (Gu, 2006). So China seems to have bypassed the pre-network CALL and stepped straightway into Web-based CALL. In the new context, we must confront some issues of practice on CALL.

A. The Model and Pedagogy of CALL

Generally speaking, there are three kinds of CALL models: 1) computer supported classroom teaching, 2) hybrid teaching, and 3) completely online course, long distance or local (Xie, 2007). These three types basically summarize the current CALL situation in China. However, the first two are much more popularly carried out than the last one which needs to proceed both in terms of research study and practical involvement.

New technologies do not only serve the new teaching/learning paradigms, they also help shape the new paradigms. The very existence of networked computers creates possibilities for new kinds of communication. A pedagogy of networked computers must therefore take a broad view, not only examining the role of information technology in language learning, but also the role of language learning in the information technology society. If our goal is to help students enter into new authentic discourse communities, and if those discourse communities are increasingly located online, then it seems appropriate to incorporate online activities for their social utility as well as for their perceived particular pedagogical value.

\section{B. CALL Software and Resources on Internet}

Where the computer is not seen as a substitute for a teacher, smaller, more limited, but more flexible software that individual teachers will use as an add-on to instruction or that will be placed in libraries as language references and resources would be more welcomed and practical. Language teachers could easily acquire this category of software, with hundreds of programs available. However, we must design some software with the thought of providing an integrated teaching solution--something that will (1) provide realistic, native-speaker models of the language in a variety of media, (2) offer a language learning curriculum,(3) do a needs assessment, (4) determine the best next step for the learner and provide practice with that skill area,(5) record what the student has done, along with an evaluation ,(6) be available at any hour and require no additional pay or benefits (Warschauer \& Healey, 1998).

One of the great benefits of the growth of multimedia is that software vendors (and language teachers) no longer feel bound to grammar practice as the main goal of computer use in the language classroom. While the process has taken longer in the foreign language arena than in English language teaching, the movement toward communicative teaching with computers is clearly taking place (Warschauer \& Healey, 1998). There are still a great many grammar and vocabulary drill programs available, but at least the vocabulary ones have started to be contextualized and to incorporate graphics, audio recording and playback, and video. Drills do have a place in language learning, particularly in the first stages of vocabulary acquisition where giving the same information in multiple modes, such as visual plus aural plus textual, enhances recognition and recall (Warschauer \& Healey, 1998). More sophisticated error-checking can provide students real help in the feedback they receive, directing them to further practice or moving them to the next stage. Those who do need extra help with those aspects of language that improve with practice can use small, focused programs to give them additional time and assistance outside of regular class time.

Another direction in current software is the integration of media. As computer storage and memory prices have 
dropped, software developers have been able to add in graphics, sound, animation, and video clips. Foreign language teachers are particularly helped by access to a variety of media to help make the language come alive to students for whom it is largely a distant abstraction. This trend can only accelerate, with faster and more powerful computers making longer video and sound clips practical. Intelligent CALL will fit the medium to the learner, ensuring that the media work in concert to enhance understanding. Developers need to restrain the urge to add anything and everything just to make a fancy-looking product, and instead focus in on selecting media to fit pedagogy, not vice-versa (Kozma, 1991). Hence, students can obtain large quantities of language data and the tools to examine the "data-driven learning". They can then build their own explanations of how language works. Having discovered the linguistic rules themselves, students are more likely to remember and use them through resources on internet.

\section{The Practitioners of CALL}

The practitioners in the new CALL era must master some basic conceptions and skills. As facilitators, teachers must in many ways know more than they would as directive givers of information. Facilitators must be aware of a variety of material available for improving students' language skill, not just one or two texts. They also need to know how to teach learners to use the material effectively. Teachers as facilitators have to be able to respond to the needs that students have, not just what has been set up ahead of time based on a curriculum developer's idea of who will be in the classroom.

Therefore, the practitioners themselves should obtain some basic skills which include: word operating and editing, electronic communication, simple internet front-page making, web resources searching, reorganizing and reusing, e-exercising and e-testing, and etc. Only with these concepts and skills, can the practitioners take advantage of the new era of CALL practice.

\section{CONCLUSION}

The role of CALL has changed greatly. Previously, it was used mainly for drills and exercises. Technological and pedagogical developments now allow us to better integrate computer technology into the language learning process. Multimedia programs incorporating speech-recognition software can immerse students into rich environments for language practice. Varied Software and large language corpora provide students' the means to investigate language use in authentic context. And the Internet allows for a great number of opportunities to communicate in the target language and multimedia information.

Future developments in networked communication, multimedia, and artificial intelligence will likely converge, creating a potentially more central role for the computer as a tool for authentic language exploration and use in the second language classroom (Warschauer \& Healey, 1998). As our focus of attention gradually shifts from the computer itself to the natural integration of computers into the language learning process, we will know that computer technology has taken its rightful place as an important element of language learning and teaching.

\section{REFERENCES}

[1] Ahmad, K., Corbett, G., Rodgers, M., Sussex, R. (1985). Computers, Language Learning and Language Teaching. Cambridge University Press, Cambridge.

[2] Gu Yueguo., Hall, C. and Hall, E. (2006). Using the Computer in ELT: Technology, Theory and Practice. Beijing: Foreign Language Teaching and Research Press.

[3] Jones, C., \& Fortescue, S. (1987). Using computers in the language classroom. London: Longman.

[4] Papert, S. (1980). Mindstorms: Children, Computers, and Powerful Ideas. New York, Basic Books.

[5] Kern, R. \& Warschauer, M. (2000). Theory and practice of network-based language teaching. In M. Warschauer \& R. Kern (Eds.), Network-based language teaching: Concepts and practice. New York: Cambridge University Press.

[6] Kozma, R.B. (1991). Learning with media. Review of Educational Research, 61, 179-211.

[7] Levy, Michael, (1997). Computer-Assisted Language Learning. Oxford: Clarendon Press.

[8] Phillips, M. (1987). Communicative language learning and the microcomputer. London: British Council.

[9] Warschauer, M., \& D. Healey. (1998). Computers and language learning: An overview. Language Teaching, 31, 57-71.

[10] Warschauer, M. (2000). "CALL for the 21st Century" IATEFL and ESADE Conference, 2 July 2000, Barcelona, Spain. Available from http://www.gse.uci.edu/markw/cyberspace.html.

[11] Xie, Tianwei. (2006). Three Kind of Modes for Chinese Language Teaching on Internet. In Yanqun Zheng, The Theoretical Study on Computer-assisted Chinese Language Teaching for Overseas. Beijing: The Commercial Press.

[12] Xie, Tianwei. (2007). Computer-assisted Foreign Language Teaching: Theory and Practice. In Jianguo Ji \& Nan Jiang (Eds.), Developments in Applied Linguistics. Beijing: China Renmin University Press.

Youwen Yang was born in Huanggang, Hubei Province, China in 1967. He received his M.A. degree in linguistics from Hubei University, China in 2002.

He is currently a PH.D candidate in Beijing Foreign Studies University and an associate professor in the School of Foreign Languages, Wenzhou University, Zhejiang, China. His research interests include Linguistics \& Applied Linguistics, Semantics, Contrastive Linguistics, and etc. 